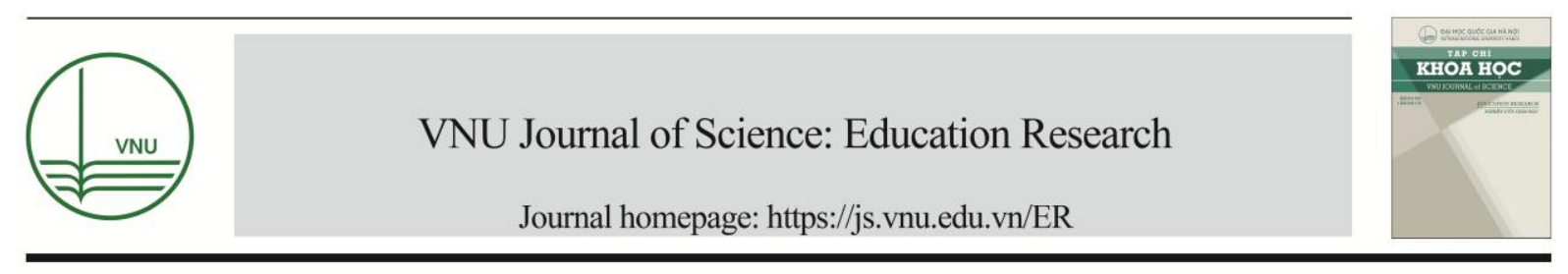

Review Article

\title{
Quality Assurance and Accreditation of Distance Education Programs in Vietnam: Rationale and Future Directions
}

\author{
Nguyen Huu Cuong*, Le My Phong \\ Vietnam Education Quality Management Agency, Ministry of Education and Training, \\ 35 Dai Co Viet, Hai Ba Trung, Hanoi, Vietnam
}

Received 03 October 2018

Revised 15 October 2018; Accepted 19 November 2018

\begin{abstract}
Distance and online education are popular training modes in the era of the Fourth Industrial Revolution and open education. Accreditation is one of the approaches that many countries across the world have implemented to assure the quality of higher education. This paper investigates the rationale and future directions for quality assurance and accreditation of distance education programs in Vietnam. First, the paper presents concepts of distance education, quality assurance and accreditation of distance education. Next, the paper reviews experiences of implementing quality assurance and accreditation of distance education from several countries in the world. Third, the paper analyses the rationale for conducting accreditation of distance education programs in Vietnam. Finally, the paper proposes three groups of recommendations for the national quality assurance organizations, accreditation agencies and higher education institutions to successfully implement the quality assurance and accreditation of distance education in Vietnam.
\end{abstract}

Keywords: Quality assurance, accreditation, distance education, online learning, higher education.

\footnotetext{
* Corresponding author.

E-mail address: nhcuong@ moet.gov.vn

https://doi.org/10.25073/2588-1159/vnuer.4176
} 


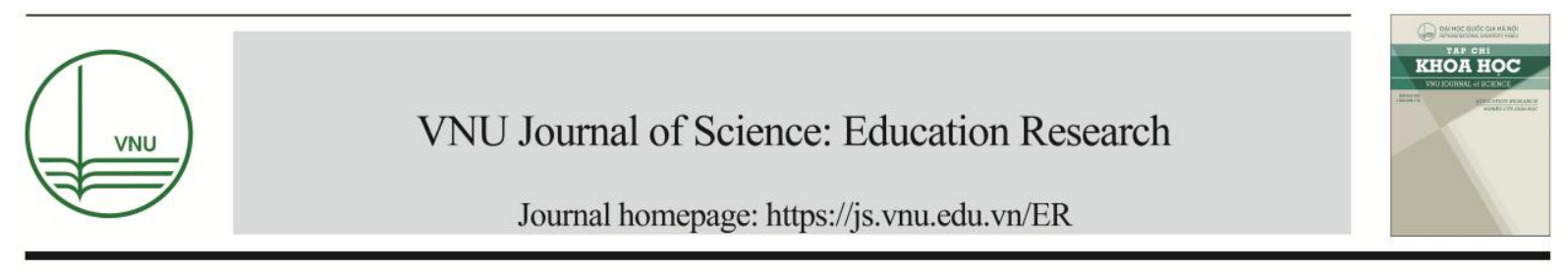

\title{
Đảm bảo và kiểm định chất lượng chương trình đào tạo đại học từ xa ở Việt Nam: Cơ sở lý luận và hướng triển khai
}

\author{
Nguyễn Hữu Cương*, Lê Mỹ Phong \\ Cục Quản lý chát luợng, Bộ Giáo dục và Đào tạo, \\ 35 Đại Cồ Việt, Hai Bà Trung, Hà Nội, Việt Nam \\ Nhận ngày 03 tháng 10 năm 2018 \\ Chỉnh sửa ngày 15 tháng 10 năm 2018; Chấp nhận đăng ngày 19 tháng 11 năm 2018
}

\begin{abstract}
Tóm tắt: Thực hiện đào tạo đại học từ xa và trực tuyến là một hình thức giáo dục phổ biến trong kỷ nguyên Cách mạng công nghiệp lần thứ tư và thời đại giáo dục mở. Kiểm định chất lượng là một trong những cách tiếp cận mà nhiều quốc gia trên thế giới áp dụng để đảm bảo chất lượng giáo dục đại học, trong đó có chương trình đào tạo từ xa. Bài viết này nghiên cứu về cơ sở lý luận và hướng triển khai đối với đảm bảo và kiểm định chất lượng chương trình đào tạo từ xa ở Việt Nam. Trước hết, nghiên cứu trình bày các khái niệm về đào tạo từ xa, đảm bảo và kiểm định chất lượng đào tạo từ xa. Thứ hai, nghiên cứu tổng hợp kinh nghiệm về đảm bảo và kiểm định chất lượng từ xa của một số quốc gia trên thế giới. Tiếp theo, bài viết phân tích cơ sở pháp lý cho việc kiểm định chất lượng chương trình đào tạo từ xa ở nước ra. Cuối cùng, bài viết đưa ra ba nhóm khuyến nghị đối với cơ quan quản lý nhà nước về đảm bảo chất lượng giáo dục đại học, tổ chức kiểm định chất lượng và cơ sở giáo dục để triển khai hiệu quả việc đảm bảo và kiểm định chất lượng đào tạo từ xa ở Việt Nam.
\end{abstract}

Tù khóa: Đảm bảo chất lượng; Kiểm định chất lượng; Đào tạo từ xa; Đào tạo trực tuyến; Giáo dục đại học.

\section{1. Đặt vấn đề}

Trong một vài thập kỷ vừa qua, đào tạo từ $\mathrm{xa}$, hay giáo dục từ xa - distance education, là một hình thức tiên phong của giáo dục mở, đã bùng nổ ở nhiều quốc gia trên thế giới, đặc biệt trong khu vực Châu Á - Thái Bình Dương. Hình thức đào tạo từ xa đã thu hút sự quan tâm

\footnotetext{
* Tác giả liên hệ.

Địa chi email: nhcuong@moet.gov.vn

https://doi.org/10.25073/2588-1159/vnuer.4176
}

của nhiều cơ sở giáo dục đại học, các chuyên gia nghiên cứu và các nhà hoạch định chính sách giáo dục. Ở nước ta, giáo dục từ xa đã phát triển được trên 20 năm và có những đóng góp đáng kể trong việc đào tạo nguồn nhân lực, đáp ứng nhu cầu học tập cho mọi thành phần, khẳng định các quan niệm về học tập suốt đời và giáo dục cho mọi người [1].

Cũng như những chương trình đào tạo theo hình thức truyền thống (đào tạo tập trung), vấn đề quản lý chất lượng và đảm bảo chất lượng các chương trình đào tạo từ xa cũng đặc biệt 
được quan tâm. Một trong những cách thức được hầu hết các hệ thống giáo dục đại học trên thế giới sử dụng là thực hiện kiểm định chất lượng các chương trình đào tạo từ xa. Bài viết này phân tích cơ sở khoa học đối với đảm bảo và kiểm đinh chất lượng đào tạo từ xa qua thực tiễn và kinh nghiệm của một số quốc gia trên thế giới. Từ đó, bài viết thảo luận hướng triển khai thực hiện đối với các chương trình đào tạo từ xa ở nước ta.

\section{Khái niệm về đào tạo từ xa và kiểm định chất lượng chương trình đào tạo từ xa}

\subsection{Các khái niệm về đào tạo tù xa}

Có nhiều khái niệm và định nghĩa về đào tạo từ xa hay giáo dục từ xa. Theo Tổ chức Giáo dục, Khoa học và Văn hóa của Liên hiệp quốc (UNESCO), thì "học tập mở (open learning) hay giáo dục từ xa (distance education) là hình thức đào tạo trọng tâm vào cách tiếp cận mở đối với giáo dục và đào tạo, giải phóng người học khỏi những hạn chế về thời gian và địa điểm, và cung cấp cơ hội học tập linh hoạt cho các cá nhân và nhóm người học" [2].

Dự án Tác động của giáo dục từ xa đối với học tập của người lớn do Chương trình học tập suốt đời của Liên minh Châu Âu tài trợ định nghĩa "giáo dục từ xa là một thuật ngữ chung chỉ các hình thức tổ chức giáo dục khác nhau trong đó giáo viên và học viên bị chia cắt bởi thời gian và không gian. giáo dục từ $\mathrm{xa}$ bao gồm giáo dục trực tuyến $(\geq 80 \%$ nội dung chương trình được thực hiện trực tuyến) và giáo dục bán trực tuyến (30-79\% nội dung chương trình được thực hiện trực tuyến), cũng như là các hình thức giáo dục khác được thực hiện với các tài liệu in ấn được chuyển phát qua đường bưu điện và/hoặc các công cụ khác để kết nối khoảng cách" [3].

Mạng lưới giáo dục Australia cho rằng đặc điểm chính của đào tạo từ xa là không yêu cầu người học phải có mặt tại lớp học và điều này cho phép họ tự do học tập ở bất cứ đâu và bất cứ khi nào họ muốn. Qua thời gian, đã có nhiều cách thức thực hiện với đào tạo trực tuyến, bao gồm việc sử dụng tài liệu bằng văn bản, video, băng tiếng và đĩa $\mathrm{CD}$. Gần đây là việc sử dụng thư điện tử và Internet, và bây giờ nhiều chương trình từ xa được gọi là học trực tuyến [4].

Ở Việt Nam, giáo dục từ xa đã được quy định trong các văn bản quy phạm pháp luật. Quy chế về tổ chức đào tạo, thi, kiểm tra, cấp chứng chỉ, văn bằng tốt nghiệp theo hình thức giáo dục từ xa được ban hành kèm theo Quyết định số 40/2003/QĐ-BGDĐT ngày 08/8/2003 của Bộ trưởng Bộ Giáo dục và Đào tạo định nghĩa "giáo dục từ xa là một quá trình giáo dục, trong đó phần lớn có sự gián cách giữa người dạy và người học về mặt thời gian và không gian. Người học theo hình thức giáo dục từ xa chủ yếu là tự học qua học liệu như giáo trình, băng hình, băng tiếng, đĩa CD-ROM, phần mềm vi tính, bằng việc sử dụng các phương tiện nghe nhìn cá nhân, phát thanh, truyền hình, các tổ hợp truyền thông đa phương tiện, mạng Internet dưới sự tổ chức, trợ giúp của nhà trường giáo dục từ xa lấy tự học là chính, đòi hỏi người học phải tự giác, kiên trì và quyết tâm cao để hoàn thành chương trình học tập của mình" (Điều 1).

\section{2. Đảm bảo và kiểm định chất luợng chuơng trình đào tạo tù xa}

Đảm bảo chất lượng đào tạo từ xa được hiểu chung là một hệ thống các chính sách, hành động, quy trình và tiêu chuẩn được xây dựng để giám sát và/hoặc nâng cao chất lượng các chương trình đào tạo từ xa. Tuy nhiên, các nhà nghiên cứu chỉ ra rằng việc đảm bảo chất lượng và kiểm đinh chất lượng chương trình đào tạo từ xa khá phức tạp và thách thức. Lý do chính là chất lượng của loại hình đào tạo này khó định nghĩa và chuẩn hóa. giáo dục từ xa liên quan đến nhiều đối tượng, bao gồm nhiều mối quan hệ như giảng viên, người xây dựng học liệu, người học, nhà quản lý, nhà cung cấp phương tiện cho đào tạo từ xa, nhà tuyển dụng lao động, chính phủ và các bên liên quan khác [5].

Nhiều nhà nghiên cứu cho rằng việc thực hiện đảm bảo chất lượng và kiểm đinh chất 
lượng liên quan đến đào tạo từ xa là một hiện tượng tương đối mới. Điều này xuất phát từ nhu cầu cần được cung cấp thông tin minh bạch và hiệu quả chi phí về loại hình đào tạo này của các bên liên quan. Cụ thể là chất lượng của các cơ sở đào tạo, chương trình đào tạo và chuẩn đầu ra của đào tạo từ xa so với đào tạo truyền thống [6].

Đã có nhiều cơ quan quản lý, tổ chức kiểm đinh chất lượng và các học giả đưa ra các bộ tiêu chuẩn đánh giá, bộ quy tắc, hướng dẫn, đối sánh để thực hiện đảm bảo và kiểm đinh chất lượng chương trình đào tạo từ xa. Mặc dù có nhiều quy định khác nhau, nhưng các bộ tiêu chuẩn đều trọng tâm vào năm nhóm vấn đề sau: (1) cam kết mạnh mẽ của cơ sở giáo dục về chất lượng của các chương trình đào tạo từ xa; (2) chương trình đào tạo và phương pháp giảng dạy phù hợp với đào tạo từ xa; (3) sự hỗ trợ đầy đủ của đội ngũ giảng viên và cố vấn học tập; (4) hình thức hỗ trợ sinh viên phong phú; và (5) phương pháp đánh giá kết quả học tập phù hợp [7]. Ngoài ra, khi triển khai đánh giá các chương trình đào tạo từ xa cần đặc biệt chú ý đến cơ sở hạ tầng kỹ thuật và công nghệ phục vụ cho chương trình đào tạo. Các đánh giá viên hoặc kiểm định viên (KĐV) có thể cần thêm nhiều bước để đảm bảo chương trình đáp ứng được các nhu cầu cụ thể của người học từ xa. Ví dụ, họ cần xem xét xem người học và giảng viên tương tác thế nào trong các lớp học trực tuyến, hoặc dịch vụ hỗ trợ sinh viên thực hiện chức năng như thế nào đối với người học từ xa [8]. Phần tiếp theo chúng tôi sẽ trình bày cụ thể kinh nghiệm và cách triển khai của một số nước trên thế giới.

\section{Kinh nghiệm thế giới về đảm bảo chất lượng và kiểm định chất lượng chương trình và cơ sở đào tạo từ xa}

Trong phần này chúng tôi tổng hợp kinh nghiệm triển khai đảm bảo và kiểm định chất lượng chương trình và cơ sở đào tạo từ xa của Hoa Kỳ, Australia, một số quốc gia ở Châu Âu và Châu Á.

\section{1. Đảm bảo và kiểm định chất lượng đào tạo tù̀ $x a$ ở Hoa Kỳ}

Là quốc gia đầu tiên trên thế giới tiến hành kiểm định chất lượng giáo dục nên Hoa Kỳ cũng có bề dày lịch sử về kiểm định chất lượng chương trình và cơ sở đào tạo từ xa. Hội đồng kiểm định chất lượng giáo dục từ xa (DEAC), thành lập năm 1926 và được Bộ Giáo dục Hoa Kỳ và Hội đồng kiểm định đại học (CHEA) công nhận hoạt động; DEAC kiểm định các cơ sở giáo dục sau phổ thông ở Hoa Kỳ và trên toàn thế giới thực hiện đào tạo từ $51 \%$ chương trình từ xa trở lên. Ngoài $\mathrm{DEAC}$, các tổ chức kiểm định quốc gia và kiểm định vùng của Hoa Kỳ cũng thực hiện kiểm định cơ sở đào tạo từ $\mathrm{xa}^{1}$.

Việc kiểm định các chương trình đào tạo từ xa do các tổ chức kiểm định chương trình được Bộ Giáo dục Hoa Kỳ và CHEA công nhận hoạt động (trong năm 2017 có 47 tổ chức kiểm định chương trình được công nhận). Ngoài việc kiểm định các chương trình đào tạo tập trung, để có thể thực hiện kiểm định các chương trình đào tạo từ xa, các tổ chức này phải đăng ký với Bộ Giáo dục Hoa Kỳ và CHEA. Mỗi tổ chức có một cách thức riêng đối với kiểm định chương trình từ xa. Một số tổ chức xây dựng bộ tiêu chuẩn kiểm định từ xa riêng như Hội đồng kiểm định giáo dục điều dưỡng (ACEN), một số tổ chức bổ sung tiêu chí vào bộ tiêu chuẩn kiểm định chương trình đào tạo tập trung để kiểm định chương trình đào tạo từ xa như Hiệp hội Phát triển giảng dạy doanh thương bậc đại học (AACSB); một số tổ chức sử dụng nguyên quy trình và bộ tiêu chuẩn kiểm định chương trình đào tạo tập trung để kiểm định chương trình đào tạo từ xa như Hội đồng Kiểm định Kỹ thuật và Công nghệ (ABET) [9].

\section{2. Đảm bảo và kiểm định chất luợng đào tạo tù $x a$ ở Australia}

${ }^{1}$ Trong năm 2017, Hoa Kỳ có 6 tổ chức kiểm định vùng và 6 tổ chức kiểm định quốc gia, 47 tổ chức kiểm đinh chương trình được CHEA công nhận. 
Hầu hết các trường đại học của Australia đều có các chương trình đào tạo từ xa, trong đó có trường có tới $85 \%$ chương trình từ xa thu hút hơn 23.000 sinh viên. Do đó, vấn đề đảm bảo chất lượng và kiểm định chất lượng đào tạo từ xa cũng được Australia đặc biệt quan tâm. Trước năm 2012, việc đảm bảo chất lượng cho hệ thống giáo dục đại học Australia bao gồm cả đào tạo từ xa do Tổ chức chất lượng các trường đại học Australia (AUQA) thực hiện. Từ năm 2012 trở đi, Tổ chức tiêu chuẩn và chất lượng giáo dục đại học (TEQSA) được thành lập trên cơ sở của AUQA, đảm nhận nhiệm vụ này. Theo quy định của Australia thì các trường đại học được trao quyền tự kiểm định các chương trình đào tạo của mình. Tuy nhiên, tất cả các chương trình và cơ sở giáo dục đại học phải thực hiện việc đăng ký quốc gia và cập nhật trên website của TEQSA. Tùy theo chất lượng và trình độ chương trình đào tạo mà các chương trình đó phải thực hiện đăng ký lại theo một khoảng thời gian nhất định (ví dụ 5 năm) [6].

Để hỗ trợ việc đảm bảo và nâng cao chất lượng đào tạo từ xa, Hội đồng giáo dục mở, từ xa và trực tuyến Australia (ACODE) đã ban hành Bộ công cụ đối sánh sử dụng công nghệ nâng cao chất lượng học tập. Bộ công cụ đối sánh này có 8 tiêu chuẩn, bao gồm: Tiêu chuẩn 1. Chính sách và quản trị của toàn bộ cơ sở giáo dục đối với công nghệ nâng cao chất lượng học tập; Tiêu chuẩn 2. Kế hoạch của toàn bộ cơ sở giáo dục để nâng cao chất lượng công nghệ phục vụ học tập; Tiêu chuẩn 3. Hệ thống công nghệ thông tin, dịch vụ và hỗ trợ việc sử dụng công nghệ nâng cao chất lượng học tập; Tiêu chuẩn 4 . Áp dụng các dịch vụ công nghệ nâng cao chất lượng học tập; Tiêu chuẩn 5. Bồi dưỡng nâng cao trình độ cho đội ngũ cán bộ, nhân viên để sử dụng hiệu quả công nghệ nâng cao chất lượng học tập; Tiêu chuẩn 6 . Hỗ trợ đội ngũ cán bộ, nhân viên để sử dụng công nghệ nâng cao chất lượng học tập; Tiêu chuẩn 7. Đào tạo sinh viên để sử dụng hiệu quả công nghệ nâng cao chất lượng học tập; Tiêu chuẩn
8. Hỗ trợ sinh viên để sử dụng hiệu quả công nghệ nâng cao chất lượng học tập [10].

\section{3. Đảm bảo và kiểm định chất lương đào tạo tù $x a$ ở Châu Âu}

Đào tạo từ xa và trực tuyến khá phổ biến ở Châu Âu. Theo thống kê trong năm 2015 có 1759 chương trình đào tạo trực tuyến được triển khai ở châu lục này. Một số quốc gia có số lượng chương trình trực tuyến lớn như Tây Ban Nha (474 chương trình), Vương quốc Anh (425 chương trình), và Pháp (267 chương trình) [11]. Tuy nhiên, theo một kết quả khảo sát về vấn đề đảm bảo và kiểm định chất lượng đào tạo từ xa được Hiệp hội các trường đại học Châu Âu giảng dạy chương trình từ xa (EADTU) công bố vào tháng 5/2017 thì hơn một nửa trong số 15 quốc gia được khảo sát không có quy định cụ thể về đào tạo từ xa và trực tuyến. Rất ít quốc gia thực hiện điều chỉnh quy trình và bộ tiêu tiêu chuẩn để đánh giá hoặc kiểm định chất lượng các chương trình đào tạo từ xa; $72 \%$ số nước không có các tiêu chuẩn và tiêu chí riêng biệt để kiểm định chất lượng các chương trình đào tạo từ xa và trực tuyến. Vương quốc Anh là một trong số ít nước đã thực hiện tốt việc đảm bảo chất lượng và kiểm định chất lượng đào tạo từ xa [12].

Ở Vương quốc Anh, Tổ chức đảm bảo chất lượng (QAA) là tổ chức độc lập, phi lợi nhuận có chức năng đảm bảo các chuẩn mực và nâng cao chất lượng các cơ sở giáo dục và chương trình đào tạo đại học nhận tài trợ từ Chính phủ Anh. Năm 2002, QAA đã ban hành Hướng dẫn học tập từ xa trong giáo dục đại học. Hướng dẫn này tập trung vào 6 nhóm vấn đề: (1) Xây dựng hệ thống; (2) Xây dựng, thông qua và rà soát chương trình; (3) Quản lý thực hiện chương trình; (4) Hỗ trợ và phát triển sinh viên; (5) Đại diện và truyền thông sinh viên; và (6) Đánh giá sinh viên [13]. Ngoài QAA, ở Vương quốc Anh còn có Hội đồng chất lượng học tập mở và từ xa (ODL $\mathrm{QC})$, được Chính phủ Anh thành lập năm 1969, để hỗ trợ nâng cao chất lượng đào tạo từ xa của các cơ sở giáo dục đại học tư thục. Bộ tiêu chuẩn của ODL $\mathrm{QC}$ được chia làm 6 nhóm, bao gồm: kết quả, nguồn lực, 
hỗ trợ, bán sản phẩm, nhà cung cấp, và hợp tác [6].

\section{4. Đảm bảo và kiểm định chất lương đào tạo tù xa ở Châu Á}

Mặc dù đào tạo mở và từ xa đã được thực hiện ở Châu Á được vài thập kỷ, nhưng chỉ đến những năm 90 của thế kỷ trước một số quốc gia ở châu lục này mới chú ý đến xây dựng các chính sách về đảm bảo chất lượng đào tạo từ xa. Vấn đề đảm bảo và đảm bảo chất lượng đào tạo từ xa ở các quốc gia Châu Á rất đa dạng. Một số nước sử dụng quy trình và tiêu chuẩn đánh giá chất lượng cơ sở giáo dục và chương trình đào tạo truyền thống để đánh giá các cơ sở và chương trình đào tạo từ xa (như Hồng Kông và Singapore). Một số quốc gia khác đã xây dựng những tiêu chí riêng biệt để đánh giá chất lượng đào tạo từ xa, ví dụ như Malaysia và Sri Lanka [6].

Cơ quan Văn bằng Malaysia (MQA), tổ chức đảm bảo chất lượng quốc gia của Malaysia đã xây dựng và ban hành Bộ quy tắc thực hành dành cho đào tạo mở và từ xa năm 2013 (dựa trên Hướng dẫn thực hiện tốt đào tạo mở và từ xa ban hành năm 2011). Bộ quy tắc này được xây dựng với mục đích hướng dẫn thực hiện kiểm định và kiểm toán các chương trình đào tạo mở và từ xa. Bộ quy tắc gồm 9 lĩnh vực và 30 tiêu chuẩn, trong mỗi tiêu chuẩn có các tiêu chí đối sánh và tiêu chí nâng cao chất lượng. Các lĩnh vực bao gồm: (1) Tầm nhìn, sứ mang, mục tiêu giáo dục và chuẩn đầu ra; (2) Thiết kế và thực hiện chương trình giảng dạy; (3) Đánh giá sinh viên; (4) Tuyển chọn sinh viên và các dịch vụ hỗ trợ; (5) Đội ngũ cán bộ giảng dạy; (6) Nguồn lực giáo dục; (7) Giám sát và rà soát chương trình đào tạo; (8) Lãnh đạo, quản trị và quản lý; và (9) Cải tiến chất lượng liên tục [14].

Sri Lanka sử dụng Bộ công cụ đảm bảo chất lượng cho cơ sở giáo dục đại học và chương trình đào tạo từ xa từ năm 2009. Bộ công cụ này do Tổ chức học tập cộng đồng (COL), Dự án hiện đại hóa giáo dục từ xa (DEMP) và UNESCO xây dựng. Có 10 tiêu chí và 386 chỉ số thực hiện áp dụng cho các cơ sở giáo dục đại học đào tạo từ xa. Các tiêu chí bao gồm: (1)
Tầm nhìn, sứ mạng và kế hoạch; (2) Quản lý, lãnh đạo và văn hóa tổ chức; (3) Người học; (4) Nguồn nhân lực và phát triển; (5) Thiết kế và thực hiện chương trình đào tạo; (6) Thiết kế và thực hiện chương trình dạy học; (7) Hỗ trợ người học; (8) Đánh giá người học; (9) Cơ sở vật chất và nguồn học liệu; và (10) Các dịch vụ tư vấn nghiên cứu và mở rộng. Có 6 tiêu chí và 276 chỉ số thực hiện đối với chương trình đào tạo từ xa. Các tiêu chí bao gồm: (1) Kế hoạch và quản lý của cơ sở giáo dục; (2) Thiết kế và thực hiện chương trình đào tạo; (3) Thiết kế và thực hiện chương trình dạy học; (4) Cơ sở vật chất và nguồn học liệu; (5) Hỗ trợ người học và sự tiến bộ; và (6) Đánh giá người học [15].

\section{Cơ sở cho việc thực hiện kiểm định chất lượng chương trình đào tạo từ xa ở Việt Nam}

\subsection{Thưc trang đào tao tù xa ở Viêt Nam}

Như đã trình bày ở các phần trước, hình thức đào tạo đại học, cao đẳng từ xa đã được triển khai ở nước ta từ đầu những năm 1990 với việc Viện Đại học Mở Hà Nội và Trường Đại học Mở Thành phố Hồ Chí Minh được Chính phủ giao nhiệm vụ đào tạo cử nhân hệ giáo dục từ xa. Cho đến nay cả nước đã có 144 chương trình đào tạo từ xa do 21 trường đại học tiến hành đào tạo. Tuy nhiên, quy mô đào tạo từ xa ở nước ta đã giảm sút trong vòng ba năm gần đây. Theo thống kê tại thời điểm tháng 10/2012, cả nước có 161.047 sinh viên theo học các chương trình đào tạo từ xa (chiếm $6 \%$ so với tổng số sinh viên cả nước) thì đến tháng 10/2016 chỉ có 70.425 sinh viên (chiếm dưới $5 \%$ so với tổng số sinh viên cả nước) và chỉ có 17 trong số 21 trường đại học được phép tiến hành đào tạo từ xa tuyển sinh được. Tỉ lệ sinh viên theo học các nhóm ngành cụ như kinh doanh - quản lý: 36\%, khoa học xã hội: 41\%, giáo dục: $15 \%$, kỹ thuật - công nghệ: 9\% $[16,17]$.

Các chuyên gia về giáo dục cho rằng một trong những nguyên nhân chính dẫn đến sự giảm sút quy mô tuyển sinh đào tạo từ xa là do chất lượng của loại hình đào tạo này chưa được 
xã hội thừa nhận. Mà lý do căn bản là từ phía các trường đại học. Nhiều trường chưa thực sự đầu tư nhân lực, công sức, tài chính để xây dựng học liệu, phát triển công nghệ đào tạo từ xa. Do đó, không ít trường đã dùng nguyên tài liệu, giáo trình đào tạo chính quy tập trung để giảng dạy từ xa. Ngoài ra, phần lớn đội ngũ giảng viên cơ hữu tham gia đào tạo từ xa chưa được đào tạo bài bản, chưa có nghiệp vụ và phương pháp giảng dạy phù hợp với loại hình này. Phương pháp kiểm tra đánh giá không phù hợp với loại hình đào tạo từ xa, việc tổ chức thi còn chưa nghiêm túc, khách quan cũng là các nguyên nhân khiến nhiều nhà tuyển dụng lao động không tuyển dụng những người tốt nghiệp các chương trình đào tạo từ xa [18].

Để xã hội, người tuyển dụng lao động tin tưởng vào chất lượng của loại hình đào tạo từ xa thì cơ quan quản lý nhà nước cần triển khai các biện pháp nhằm khắc phục những hạn chế, bất cập và chấn chỉnh, xử lý những hiện tượng tiêu cực. Một trong những giải pháp mà nhiều chuyên gia đề xuất là Bộ Giáo dục và Đào tạo cần ban hành văn bản cụ thể về đảm bảo chất lượng đào tạo từ xa, đồng thời tiến hành kiểm định chất lượng tất cả các chương trình đào tạo từ xa trên cả nước.

\subsection{Quy định và triển khai kiểm định chất luơng giáo duc đại hoc ở Việt Nam}

Đảm bảo và kiểm định chất lượng giáo dục đại học đã chính thức được triển khai ở nước ta từ năm 2004 với việc Bộ trưởng Bộ Giáo dục và Đào tạo ban hành Quy định tạm thời về kiểm định chất lượng trường đại học (Quyết định số 38/QĐ-BGDĐT ngày 02/12/2014). kiểm định chất lượng ở Việt Nam là bắt buộc đối với tất cả các cơ sở giáo dục và chương trình đào tạo đại học (Luật Giáo dục đại học, Điều 49 khoản 2). Để triển khai các quy định của Quốc hội và Chính phủ về kiểm định chất lượng giáo dục, Bộ Giáo dục và Đào tạo đã ban hành các văn bản về quy trình và chu kỳ kiểm định chất lượng cơ sở giáo dục đại học và chương trình đào tạo, các bộ tiêu chuẩn đánh giá chất lượng trường đại học và chương trình đào tạo các trình độ của giáo dục đại học, quy định về tổ chức kiểm định chất lượng giáo dục và kiểm định viên kiểm định chất lượng giáo dục [19].

Cho đến hết tháng $8 / 2016$, kết quả triển khai kiểm định chất lượng giáo dục đại học theo tiêu chuẩn của Bộ Giáo dục và Đào tạo đạt được cụ thể là: có 218 trường đại học, học viện hoàn thành báo cáo tự đánh giá; 124 trường được các tổ chức kiểm định chất lượng đánh giá ngoài, trong đó 117 trường được công nhận đạt tiêu chuẩn chất lượng. Về kiểm định chất lượng chương trình đào tạo, đã có 12 chương trình được đánh giá ngoài (trong đó 10 chương trình đã được công nhận đạt tiêu chuẩn chất lượng). Ngoài ra còn có 06 trường đại học và 107 chương trình đào tạo được đánh giá hoặc kiểm định theo tiêu chuẩn của khu vực, quốc tế $[20,21]$.

Về đảm bảo và kiểm định chất lượng đào tạo từ xa, Đề án "Phát triển đào tạo từ xa giai đoạn 2015-2020" được Thủ tướng Chính phủ phê duyệt theo Quyết định số 1559/QĐ-TTg ngày 10/9/2015 đã đặt ra mục tiêu cụ thể đến năm 2020 phải tiến hành kiểm định tất cả các chương trình đào tạo từ xa cấp văn bằng đã được cấp phép. Các trường thực hiện đào tạo từ xa cũng được khuyến khích tham gia kiểm định bởi các tổ chức quốc tế có uy tín. Để triển khai Đề án này, ngày 22/6/2016, Bộ Giáo dục và Đào tạo đã ban hành Kế hoạch số $431 / \mathrm{KH}-$ BGDĐT thực hiện Đề án "Phát triển đào tạo từ xa giai đoạn 2015-2020", trong đó giao Cục Khảo thí và kiểm định chất lượng giáo dục (nay là Cục Quản lý Chất lượng) chủ trì, phối hợp với các đơn vị liên quan xây dựng Thông tư ban hành bộ tiêu chuẩn đánh giá chất lượng chương trình đào tạo từ xa và các văn bản hướng dẫn triển khai. Ngoài ra, Quy chế đào tạo từ xa trình độ đại học được ban hành kèm theo Thông tư số 10/2017/TT-BGDĐT ngày 28/4/2017 của Bộ trưởng Bộ Giáo dục và Đào tạo cũng nêu rõ phải triển khai tự đánh giá chương tình đào tạo từ xa, đăng ký tham gia kiểm định chất lượng chương trình đào tạo từ xa theo quy định hiện 
hành với tổ chức kiểm định chất lượng (Điều 11, khoản 7).

\section{Một số khuyến nghị}

Theo như phân tích ở trên thì việc kiểm định chất lượng đào tạo từ xa là bắt buộc ở nước ta và đến hết năm 2020 tất cả các chương trình đào tạo từ xa phải được kiểm định chất lượng. Trong ba cách thức kiểm định chương trình đào tạo từ xa mà thế giới đang thực hiện là: (1) sử dụng nguyên bộ tiêu chuẩn đánh giá chất lượng chương trình đào tạo tập trung, (2) thêm một số tiêu chí vào bộ tiêu chuẩn đánh giá chất lượng chương trình đào tạo tập trung, và (3) xây dựng một bộ tiêu chuẩn riêng biệt, thì Việt Nam chọn cách thức thứ 3 - xây dựng một bộ tiêu chuẩn mới để kiểm định chất lượng các chương trình đào tạo từ xa. Trong phần này, chúng tôi sẽ trình bày một số khuyến nghị đối với việc xây dựng bộ tiêu chuẩn đánh giá chất lượng và triển khai kiểm định chất lượng chương trình đào tạo từ xa trong thời gian tới. Ba nhóm khuyến nghị được đưa ra đối với cấp quản lý nhà nước về đảm bảo và kiểm định chất lượng, tổ chức kiểm định chất lượng và cơ sỏ giáo dục có đào tạo từ xa.

\section{1. Đối với cơ quan quản lý nhà nước}

Đối với cơ quản quản lý nhà nước về đảm bảo và kiểm định chất lượng giáo dục, mà cụ thể là Bộ Giáo dục và Đào tạo thì điều quan trọng nhất là phải tiến hành xây dựng và ban hành bộ tiêu chuẩn đánh giá chất lượng chương trình đào tạo từ xa. Bộ tiêu chuẩn này cần đảm bảo những tiêu chí thể hiện sự quản lý nhà nước về giáo dục từ xa, đồng thời phải có những tiêu chí tiếp cận với xu thế khu vực và quốc tế. Ban soạn thảo có thể tham khảo các bộ tiêu chuẩn kiểm định từ xa của các nước phát triển trên thế giới như Hoa Kỳ, Vương quốc Anh và Australia. Trong đó, bộ công cụ đảm bảo chất lượng đào tạo trực tuyến do TEQSA, Australia biên soạn để áp dụng cho các nền kinh tế APEC là nguồn tham khảo có giá trị. Bộ tiêu chuẩn đánh giá chất lượng chương trình đào tạo từ xa của Việt Nam cần có những tiêu chí đặc thù của đào tạo từ xa như hạ tầng công nghệ thông tin, nguồn học liệu phục vụ đào tạo từ xa, năng lực của giảng viên và cán bộ hỗ trợ đào tạo từ xa, tương tác giữa giảng viên và học viên, hỗ trợ sinh viên, và phương pháp đánh giá phù hợp. Ngoài việc ban hành bộ tiêu chuẩn đánh giá chất lượng chương trình đào tạo từ xa, Bộ Giáo dục và Đào tạo cũng cần xây dựng tài liệu hướng dẫn sử dụng bộ tiêu chuẩn này, chi tiết tới từng chỉ báo và minh chứng để các cơ sở giáo dục có chương trình đào tạo từ xa, các tổ chức kiểm định chất lượng giáo dục và các kiểm định viên kiểm định chất lượng thống nhất thực hiện. Bên cạnh đó, cần ban hành văn bản chỉ đạo việc tổ chức và giám sát các hoạt động đảm bảo chất lượng bên trong của các cơ sở giáo dục về đào tạo từ xa để đảm bảo rằng hoạt động kiểm định chất lượng mang tính quá trình, chứ không phải hoạt động kiểm định chất lượng mang tính tổng kết như hiện nay.

\section{2. Đối với các tổ chức kiểm định chất lương giáo duc}

Để thực hiện tốt việc đánh giá các chương trình đào tạo từ xa, các tổ chức kiểm định chất lượng giáo dục cần chú ý đến năng lực chuyên môn của đội ngũ kiểm định viên. Cần tổ chức các khóa tập huấn để trang bị kiến thức, kỹ năng cho các kiểm định viên sẽ tham gia đánh giá ngoài các chương trình đào tạo từ xa. Để tham gia đánh giá chương trình đào tạo từ xa, các kiểm định viên ngoài kinh nghiệm đánh giá chương trình đào tạo truyền thống, cần thực sự am hiểu về đào tạo từ xa. Vì kiểm định đào tạo từ xa hoàn toàn mới mẻ ở nước ta, nên các kiểm định viên cần phải được trang bị những kỹ thuật và phương pháp để đánh giá chuẩn xác chất lượng các chương trình đào tạo từ xa.

\section{3. Đối với các co sở giáo duc có thực hiện chuoong trình đào tạo tù xa}

Cơ sở giáo dục có thực hiện chương trình đào tạo từ xa cần chuẩn bị nhân lực và vật lực để thực hiện tốt các bước trong quy trình kiểm định chất lượng chương trình đào tạo. Trước hết cần tổ chức tập huấn cho toàn bộ cán bộ quản lý, giảng viên, cán bộ hỗ trợ, nhân viên, và sinh viên cốt cán về tầm quan trọng và quy trình kiểm định chất lượng. Ngay khi bộ tiêu chuẩn 
đánh giá chất lượng chương trình đào tạo từ xa được ban hành, cần thành lập Hội đồng tự đánh giá và tiến hành tự đánh giá, viết báo cáo tự đánh giá các chương trình từ xa mà trường tổ chức đào tạo. Tiếp đó, tổ chức rà soát, bổ sung và hoàn thiện các chỉ báo còn chưa hoàn thiện thông qua các hoạt động đảm bảo chất lượng bên trong, sau đó mớithực hiện đăng ký đánh giá ngoài với một tổ chức kiểm định chất lượng được Bộ Giáo dục và Đào tạo cấp phép ${ }^{2}$. Các trường cũng được khuyến khích thực hiện đánh giá hoặc kiểm định với một tổ chức nước ngoài có uy tín được Bộ Giáo dục và Đào tạo công nhận.

\section{Kết luận}

Đào tạo từ xa, đào tạo trực tuyến ngày càng trở nên phổ biến trong các hệ thống giáo đại học trên thế giới. Hình thức đào tạo này được coi là một công cụ hữu hiệu phục vụ việc học tập suốt đời. Đào tạo từ xa với việc áp dụng công nghệ thông tin là phương thức giáo dục hiện đại, phổ biến đến mức độ chủ đạo trong kỷ nguyên giáo dục mở và cách mạng công nghiệp 4.0. Để giáo dục từ xa phát huy được những thế mạnh, nhằm đào tạo ra đội ngũ lao động vừa làm vừa học có tri thức, kỹ năng thì cần có các biện pháp để đảm bảo và nâng cao chất lượng hình thức đào tạo này.

Được sử dụng bởi nhiều quốc gia trên thế giới qua nhiều thập kỷ, kiểm định chất lượng đã chứng tỏ là một cách tiếp cận đảm bảo chất lượng có hiệu quả đối với giáo dục đại học nói chung và giáo dục từ xa nói riêng. Với quy định kiểm định chất lượng bắt buộc các cơ sở giáo dục và chương trình đào tạo đại học, đặc biệt là kiểm định xong tất cả các chương trình đào tạo từ xa đến năm 2020, cho thấy Việt Nam đang thể hiện quyết tâm để đảm bảo chất lượng phương thức đào tạo này. Với một hệ thống kiểm định chất lượng còn khá non trẻ, chúng ta cần nỗ lực và cố gắng nhiều hơn nữa để có thể thực hiện được mục tiêu này. Cụ thể là cấp quản lý nhà nước cần sớm ban hành bộ tiêu

\footnotetext{
Đến 9/2018 Việt Nam đã có 05 tổ chức kiểm định chất lượng giáo dục được thành lập, trong đó có 04 tổ chức được cấp phép hoạt động.
}

chuẩn đánh giá chất lượng chương trình đào tạo từ xa và hướng dẫn phù hợp, các tổ chức kiểm định chất lượng cần trang bị kiến thức và kỹ năng chuyên biệt về kiểm định từ xa cho đội ngũ kiểm định viên, và các cơ sở giáo dục cần chuẩn bị các nguồn lực cần thiết để tiến hành kiểm định chất lượng các chương trình đào tạo từ xa đang thực hiện đào tạo.

\section{Tài liệu tham khảo}

[1] UNESCO, Distance education in Asia and the Pacific: country papers, Volume III (Singapore Vietnam), 2009. www.unesco.org/education/pdf/5323c.pdf.

[2] UNESCO, Open and distance learning: trends, policy and strategy considerations, 2002. http://unesdoc.unesco.org/images/0012/001284/1284 63e.pdf.

[3] Owusu-Boampong, A. \& Holmberg, C., Distance education in European higher education - the potential, UNESCO Institute for Lifelong Learning, International Council for Open and Distance Education and Study Portals B.V, 2015.

[4] Australian University, Distance learning Australia, 2018.http://www.australianuniversities.com.au/distanc e-learning/.

[5] O. Darojat, M. Nilson, D. Kaufman, Quality assurance in Asian open and distance learning: policies and implementation, Journal of Learning for Development. Vol. 2, No. 2 (2015) 1.

[6] I. Jung, C. Latchem, Quality assurance and accreditation in distance education and e-learning: models, policies and research, Routledge, London, 2012.

[7] Wang, Qi., Quality assurance - best practices for assessing online programs, International Journal on Elearning. Vol. 5, No. 2 (2006) 265.

[8] J. Friedman, 10 facts about accreditation in online degree programs, U.S.News \& World Report, February 9, 2017. https://www.usnews.com.

[9] U.S. Department of Education., Accrediting agencies recognized for distance education and correspondence education, 2018. https://www2.ed.gov.

[10] The Australasian Council on Open, Distance and e-learning (ACODE), Benchmarks for technology enhanced learning, ACODE, Canberra, 2014.

[11] L. Bollaert, NVAO's accreditation of online education in a nutshell, https://www.nvao.net, 2015.

[12] P. Henderikx, G. Ubachs, Quality assurance and accreditation of online and distance higher education, https://www.unic.ac.cy, 2017. 
[13] A. Stella, A. Gnanam, Quality assurance in distance education: The challenges to be addressed, Higher Education. Vol. 47, No. 2 (2004) 143.

[14] Malaysian Qualification Agency (MQA), Code of practices for open and distance learning, MQA, Kuala Lumpur, 2013.

[15] COL, DEMP \& UNESCO, Quality assurance toolkit for distance higher education institutions and programmes, COL, Vancouver, 2009.

[16] Vietnamnet, Mở đào tạo từ xa sẽ không cần cấp phép, http://vietnamnet.vn, 2017.

[17] Tertiary Education Quality and Standards Agency (TEQSA), Quality assurance of online learning: discussion paper, TEQSA, Melbourne, 2017.
[18] Nhân dân Điện tử, Phát triển đào tạo từ xa đúng hướng, http://www.nhandan.com.vn, 2017.

[19] Nguyễn Hữu Cương, Một số kết quả đạt được của kiểm định chât lượng giáo dục đại học Việt Nam và hướng triển khai trong tương lai, Tạp chí Quản lý Giáo dục. Tập 9 Số 8 (2017) 7.

[20] Cục Quản lý Chất lượng - Bộ Giáo dục và Đào tạo, Danh sách các cơ sở giáo dục đại học; các trường cao đẳng, trung cấp sư phạm, đã hoàn thành báo cáo tự đánh giá, được kiểm định, 2018 (dữ liệu cập nhật đến ngày 31/8/2018).

[21] Cục Quản lý Chất lượng - Bộ Giáo dục và Đào tạo, Danh sách các chương trình đào tạo được đánh giá/công nhận, 2018 (dữ liệu cập nhật đến ngày 31/8/2018). 